\title{
THE CORRELATIONAL RELATIONSHIP BETWEEN PHYSICAL CHARACTERISTICS, ACTIVITIES, AND SENSE OF PLACE OF A PUBLIC SPACE
}

\author{
Rafidah Azzar Dea*, Hanson E. Kusuma** \\ *) Master Student, Architecture Program, Institut Teknologi Bandung, Indonesia \\ **) Architecture Program, Institut Teknologi Bandung, Indonesia \\ e-mail: rafidahdea@gmail.com
}

\begin{abstract}
Public space is one of the important elements in a city to accommodate the citizen to do various things. However, it is not uncommon for public spaces to be ignored or unused by the community. Looking at this phenomenon, this study aims to look at the relationship between physical characteristics, activities, and sense of place of a public place. The research used qualitative methods in the first stage and quantitative methods in the second stage. The first stage explores the physical characteristics and activities in public spaces, as well as the user's perceived sense of place. The second stage reveals the correlational relationship between dimensions of physical characteristics, activities, and sense of place. From the results of the correlational analysis, it is revealed that the physical characteristics of the natural environment encourage a sense of meaningful place and encourage refreshing activities which also encourage a sense of meaningful place. In addition, productive activities are carried out by the physical character of the arts and kept away by the physical characteristics of the social atmosphere and parking, as well as encouraging a sense of meaningful place. The physical character of the novelty encourages recreational activities and discourages socialization. In addition, the physical character of accessibility also encourages recreational and socialization activities. As for the physical character, many choices encourage socialization and consumptive activities which then create a sense of only knowing a space.
\end{abstract}

Keywords: activities, physical characteristics, public space, sense of place, visiting motivation

\section{INTRODUCTION}

From all the bustle of the city, we can see that the intensity of activities happening in a city is increasing. Continuous urban development results in the bustle and density of the city. With the rapid development of a city, space is needed to accommodate it, especially public spaces. Public space is a very useful space because it can accommodate various activities in it. Judging from the spatial arrangement of the 
city, the existence of public space can be a binding space for the city to become a link between the spaces within the city (Iswanto, 2006).

According to Carr (1992), public space is a common space that is easily accessed by all people for activities, either individually or in groups. Public space can also be interpreted as a place that can bring economic benefits and as a place for people to gather to express solidarity and express opinions (Henry, 2008). The public space has a function as a node and communicative means as well as a social binder to create interactions between community groups, as well as a place to gather daily and on special occasions (Haryanti, 2008). In addition, the public space has benefits and advantages in improving the economy, bringing benefits to human health, means of socializing, protecting the environment (Carmona et al., 2008).

Considering the city as an urban area, especially its public space as a place to have fun, work, argue, and so on, it must be able to meet the emotional, social, and physical needs of residents and visitors. Boyer (1994) states that planning a city and its architectural projects always has a utopian mindset, that is, society will be better off towards its future. Rossi (1986) emphasized that a person's memory of a city is greatly influenced by the image of the city. The image of the city is influenced by events in the city that occur because of the existence of public spaces as spaces for interaction. From this, we can see the importance of the role of public space in a city. Even the public space has become part of the 2016-2020 Ministry of Public Works Strategic Plan, as an activity that requires specific handling.

But unfortunately, it is not uncommon for public spaces to be abandoned or ignored by the people. This is caused by several problems, such as privatization and the presence of virtual public spaces. The debate about privatization has been growing for a long time. Some public spaces have started to set entry prices and can only be accessed by certain groups due to the nuances they create. Besides that, the open space surrounded by the building makes its openness limited so that it is only used by people who have special purposes. Especially now that virtual public spaces are developing along with the development of ICT (Information Communication Technology), which is an artificial virtual or imaginary space. In this public space, everyone can do whatever they are used to in their daily social life in a new way. During its development, critical thinking about capitalization and privatization led to normative ideas about how cities should be. Until finally the criticism boils down to the idea of presenting the human side of the city and the importance of paying attention to the city community (Setiawan, 2006).

To achieve this, there are several qualities and successes of public space that need attention. Beqaj (2016) states that the quality of public space that relates to its citizens has three main factors, namely usability, inclusiveness, and access and justice. On the other hand, Francis (1998) also mentions several criteria for the success of public spaces, namely diversity of users, level of comfort, accessibility to anyone, giving spatial meaning, and improving ecological quality.

From these criteria, it can be seen that the success of the public space cannot be separated from its users. Public spaces that support children, adults, and communities encourage interaction between generations helping to create caring individuals who can share the values and joyful experiences they need. Then this feeling eventually creates a bond with the public space. In addition, by building a 
public space that supports interaction between generations and is supported by programs and policies, social support can be created for people's lives and increases a sense of community, a sense of memory, and history (Kaplan et al., 2002). Inclusive practices must be involved so that individual and diverse practices can be transformed into collaborative practices (Petrescu et al., 2016). Sometimes groups of residents, business owners, and other parties form a grass-rooted organization that ultimately manages the public space. This model is called the 'grassroots partnership model' (Androulaki et al., 2020). With this participation, the image of the city is no longer a determination of the desires from the top (top-down approach) but becomes the desire of the community which is realized from above (bottom-up approach). So that it creates a sense of belonging to the public space by the community and that public space can be used and beneficial to its full potential.

This sense of belonging is important to think about given the existence of public space problems that are ultimately abandoned by its users. To avoid this, it is necessary to make efforts to make users have an attachment or sense of place to the public space. Shamai (1991) classifies the sense of place into seven levels, namely not having a sense of place, knowing being in a place, belonging to a place, being attached to a place, identifying with the purpose of a place, being involved with a place, and finally being sacrificing for a place. From these levels can be implied a process of sense of place, in which it develops from having no sense of place at all to sacrifice for that place.

To achieve a sense of place, of course, quality public spaces are needed. Beqaj (2016) states that the quality of public space is closely related to the activity framework that develops in it. Carr (1992) also explains that to optimize the use of public space, two factors must be considered, namely the use of space and the context and form of space (space form and context). The use of public space means the existence of different spaces are capable of accommodating different functions and activities. Meanwhile, context and spatial form are defined as physical characters in space, where the physical boundaries and interesting objects used can be used as markers of the shape of the space.

To understand further the meaning of space that is capable of accommodating different activities, it is also necessary to understand the various activities that may occur. The meaning of activity in a space can be divided into three kinds of activities (Gehl, 1987), namely main activities, choice activities, and social activities. These three types of activities can be found in public spaces. Apart from that, the public space also needs to anticipate other activities that might be created outside of the predicted activities. A variety of activities can be created due to the diversity of facilities and the diversity of users.

The activity itself can of course be influenced by the physical characteristics that exist in a public space. The key to environmental psychology is to describe specific type preferences for a physical hue (Meagher \& Marsh, 2017). In his research, Adhitama (2013) also found that there are determinants of physical hue that affect users in their activities in public spaces, including the presence of shade rooms, rest spaces, activity spaces, and accessibility.

Talking about the physical characteristics of public spaces, according to Trancik, there are two kinds of public spaces, namely hard space and soft space. In 
principle, hard space is limited by an architectural wall that is used as a place for social activities and has an important factor in the form of an enclosure creation. The enclosure creation itself includes three main components, namely a threedimensional frame, a two-dimensional pattern, and objects in space. Meanwhile, soft space includes everything that is dominated by natural materials such as gardens. The design of this soft space is also very important considering that the design can create contrasting conditions with a city environment that is full of built physical environments.

If we look back, it seems that the success of public spaces depends on how the users perceive the public space. Of course, these users have activities in public spaces, where these activities are also influenced by the physical characteristics of the public space. Therefore, this study aims to determine the relationship between physical characteristics, activities, and the sense of place of public space. This relationship can then become a designer's reference for designing public spaces by the motivation of visitors, namely in the form of physical characteristics and activities. That way, it can create a sustainable public space that is not neglected or abandoned by the community, given the important role of public space in a city.

\section{RESEARCH METHODS}

This research uses a mixed-method approach (Creswell, 2011). This method is used to reduce the bias that may occur. In the first stage, qualitative research was conducted to explore the reasons for the visit, which were further divided into physical characteristics and activities. Then at the next stage quantitative research is carried out to reveal the correlational relationship between physical characteristics, activities, and a sense of place.

At the qualitative stage, questionnaires were distributed online to find out why users visit public spaces. The public space choice itself was left to the respondents, whichever public space they visit most often. This stage uses a grounded theory approach (Creswell, 2012) with open questions to allow respondents to answer freely. Data collection was carried out for one week in September 2020 using nonrandom sampling methods and snowball techniques, which is sending questionnaires from one person to another (Kumar, 2005). From the data collection, there were 224 respondents. The data collected from open-ended questions were analyzed by categorizing the keywords that represent them (content analysis). The results are the major categories of reasons for visiting public spaces, including refreshing, recreation, attractiveness, comfort, atmosphere, activities, and accessibility.

In the second stage which is the quantitative stage, those keywords obtained from the qualitative stage of the content analysis results are developed. The categories of reasons for visiting are divided into groups of physical characteristics and activities. In addition, these categories are also compared with the results of theoretical studies, namely the sense of place.

Physical characteristics were divided into four main categories, each of them consisting of the keywords from the first stage. The categories were accessibility (near home, near to other facilities, near transportation, and accessible), 
attractiveness (wide, unique, parking, curious, photogenic, food, store, famous, view, aesthetic, limited choice, behavior, complete facilities, affordable prices, waiting for a place, learning about culture, craft exhibition, and neat), convenience (comfortable, cool, calm, clean air, not noisy, rest, and clean), and environment (enjoyable, natural atmosphere, crowded, night atmosphere, new atmosphere, openness, and beautiful).

The activity was divided into three main categories, each of them consisting of the keywords from the first stage. The categories were doing an activity (socializing, culinary, exercising, shopping, working, watching activity, meeting point, attending the event, and recreating), refreshing (chilling, need refreshing, getting fresh air, relaxing, looking for inspiration, healing, bored, and me time), and recreation (recreation, strolling, entertainment, photo hunting, live music, playing, learning culture, and sight-seeing).

Sense of place was divided into six main categories based on the level of sense of place, which each of them consisting of their keywords from the theory itself. The categories were knowledge of being located in a place (know the location and not memorable), belonging to a place (feelings of longing and getting used to it), attachment to a place (thing to be told and very meaningful), identifying with the place goals (loyalty and satisfied), involvement in a place (play an active role and dedication), and sacrifice for a place (commitment and sacrifice).

In general, the questionnaire consists of four main parts. The first part is about the demographics of the respondents such as gender, age, occupation, income, expenditure, domicile, and also about the public spaces they like to visit the most, namely in the form of the name, intensity, and duration. The second part discusses the physical characteristics in public spaces which consist of 4 categories and 35 measurable variables obtained from the first stage. The third part is followed by questions about activities in public spaces which consist of 3 categories and 24 measurable variables obtained from the first stage. The last is the part regarding the sense of place, which according to Shamai (1991), there are 7 levels. However, in this questionnaire only 6 levels were used, ignoring the first level, which was no sense of place at all.

Table 1. Example of Closed Question with Linkert Scale.

\begin{tabular}{cccccccc}
\hline Variable & Scale \\
\hline \multirow{2}{*}{$\begin{array}{c}\text { Physical } \\
\text { Characteristics }\end{array}$} & Strongly Disagree & 1 & 2 & 3 & 4 & 5 & Strongly Agree \\
\cline { 2 - 6 } & \multirow{5}{*}{ Activities } & Get together and chat with other people \\
\cline { 2 - 6 } & Never & 1 & 2 & 3 & 4 & 5 & Very Often \\
\hline \multirow{2}{*}{ Sense of Place } & I only know the location of the public space \\
\cline { 2 - 6 } & Strongly Disagree & 1 & 2 & 3 & 4 & 5 & Strongly Agree \\
\hline & Source: Dea and Kusuma, 2021 & \\
\end{tabular}


Data collection was carried out with closed questions (Table 1). Questions use a continuous Likert scale 1-5. For the physical character and sense of place, the scale from lowest to highest strongly disagrees, disagree, neutral, agree, and strongly agree. As for the portion of the activity, the scale from lowest to highest was never, very rarely, rarely, often, and very often.

The data was collected by distributing online questionnaires by non-random sampling using the snowball technique. This collection took place from 22 October 2020 to 9 November 2020 and collected 162 respondents. Respondents are people who have visited public spaces before. The ratio of female and male respondents tends not to be much different, namely $57 \%$ female and $43 \%$ male. Among them, $77 \%$ were less than 23 years old, $14 \%$ between $23-25$ years old, $4 \%$ between $26-30$ years old, and more than 30 years old 5\%. Most of the respondents were students $(52 \%)$, followed by workers $(31 \%)$ and the least were unemployed $(17 \%)$. Respondents were domiciled from various regions, especially from Bandung, Bekasi, and Jakarta.

Furthermore, numerical data from each variable were analyzed quantitatively by factor analysis (FA). FA is obtained from principal component analysis (PCA) with varimax rotation to obtain various latent variables/dimensions that represent the measured variables. Measured variables are reduced to latent variables which represent the most variation in principal components. The number of latent variables that represent each measured variable is obtained using the eigenvalue that appears when the factor analysis is carried out. What is taken is the factor whose eigenvalue is more than 1. The latent variable is then given a name that represents the various measured variables in the latent variable. Finally, multivariate correlation analysis was carried out to determine the correlational relationship between latent variables. Latent variables are further called dimensions.

\section{RESULTS AND DISCUSSION}

PCA was performed for measured variables of the reason for visiting and sense of place. The reasons for visiting are divided into two aspects, namely physical characteristics, and activities. The PCA process between the two aspects is also made separately to make the naming of latent variables easier.

\section{Physical Characteristics Dimensions}

From the results of the PCA of physical characteristics, it was found eight main components with an eigenvalue of more than one. The eight components which then become latent variables are considered sufficient to represent the phenomenon of measurable variables from physical characteristics. The latent variables obtained from these measured variables can be seen in Table 2 . The eight latent variables are natural environment, novelty, many choices, accessibility, neatness and cleanness, social atmosphere, art, and parking. 
Table 2. Factor Analysis of Physical Characteristics of Public Spaces

\begin{tabular}{|c|c|c|c|c|c|c|c|c|}
\hline & 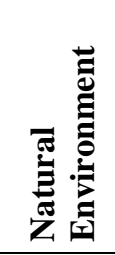 & 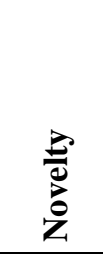 & 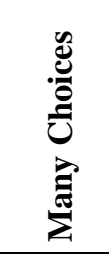 & 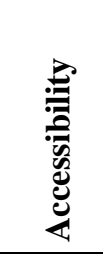 & 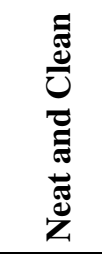 & 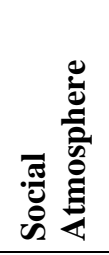 & 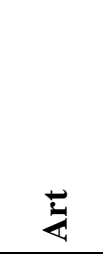 & 番 \\
\hline Mean & 3,60 & 3,49 & 3,34 & 3,85 & 3,59 & 3,88 & 2,59 & 3,47 \\
\hline$\alpha$-Cronbach & 0,90 & 0,79 & 0,79 & 0,74 & 0,76 & 0,50 & 0,67 & - \\
\hline Variance & 6,06 & 3,62 & 2,93 & 2,69 & 2,20 & 1,98 & 1,77 & 1,64 \\
\hline Cum percent & 17,32 & 27,65 & 36,03 & 43,72 & 50,02 & 55,67 & 60,72 & 65,42 \\
\hline
\end{tabular}

Table 3. Mean and Loading Factor of Each Physical Characteristics Variables (continued)

\begin{tabular}{llcc}
\hline Dimensions & Variable & Mean & Loading Factor \\
\hline Natural Atmosphere & 3,56 & 0,77 \\
Clean air & 3,66 & 0,76 \\
Calm & 3,60 & 0,75 \\
Cool & 3,96 & 0,74 \\
& Rest & 3,27 & 0,72 \\
Natural Environment & Not noisy & 2,99 & 0,72 \\
& Comfortable & 3,92 & 0,70 \\
& Beautiful & 3,72 & 0,68 \\
& Enjoyable & 3,98 & 0,57 \\
& View & 3,70 & 0,57 \\
& Near home & 3,22 & 0,40 \\
\hline Unique & 3,74 & 0,66 \\
Curious & 3,20 & 0,65 \\
Nowelty & 3,66 & 0,64 \\
& Aesthetic & 3,82 & 0,63 \\
Photogenic & 3,46 & 0,57 \\
Night atmosphere & 3,40 & 0,55 \\
Famous & 3,15 & 0,53 \\
\hline
\end{tabular}


Dea, Kusuma: THE CORRELATIONAL RELATIONSHIP BETWEEN PHYSICAL CHARACTERISTICS, ACTIVITIES, AND SENSE OF PLACE OF A PUBLIC SPACE

\begin{tabular}{llcc}
\hline Dimensions & Variable & Mean & Loading Factor \\
\hline \multirow{2}{*}{ Many choices } & Food & 3,52 & 0,87 \\
& Store & 3,1 & 0,86 \\
& Affordable prices & 3,39 & 0,64 \\
\hline \multirow{3}{*}{ Accessibility } & Near transportation & 3,61 & 0,82 \\
& Accessible & 4,07 & 0,76 \\
& Near to other facilities & 3,81 & 0,74 \\
& Wide & 4,12 & 0,51 \\
& Waiting for place & 3,61 & 0,35 \\
\hline \multirow{3}{*}{ Neat and clean } & Neat & 3,71 & 0,71 \\
& Clean & 3,75 & 0,67 \\
& Complete facilities & 3,33 & 0,58 \\
\hline \multirow{2}{*}{ Social atmosphere } & Behavior & 3,69 & 0,73 \\
& Openness & 4,06 & 0,60 \\
& Crowded & 3,91 & 0,48 \\
\hline \multirow{2}{*}{ Art } & Learning about culture & 2,75 & 0,80 \\
\hline & Craft exhibition & 2,43 & 0,75 \\
\hline & Parking & 3,47 & 0,58 \\
\hline
\end{tabular}

From the results of the factor analysis, it can be seen that the social atmosphere with the highest average value indicates that this variable is a motivation in the form of the most dominant attraction in a public space. This variable shows the atmosphere in a public space from a social perspective. As for what is included in this latent variable, there is a diversity of behavior, open space, and crowded. The most dominant variable in this category is openness. From this, it can be seen that visitors to public spaces tend to like open spaces rather than closed ones.

Apart from the social atmosphere, accessibility is also a dominant attraction in a public space. Accessibility shows the degree of ease with which these public spaces can be reached. In this case, this includes proximity to public transportation and other facilities, ease of access, wide, and can be used as a place to wait. The most dominant factors in this category are wide and ease of access. So, it is necessary to pay attention to how wide a public space is and how it can be accessed by various groups.

Below are natural environmental factors that include things related to the comfort of the natural environment without human intervention, such as natural atmosphere, clean air, calm, cool, can rest, not noisy, comfortable, enjoyable, has views, and near home. Meanwhile, the most dominant factor is enjoyment, followed by the cool and comfortable factor. 
The next dominant category is neat and clean which indicates the physical elements or facilities provided and their quality. Included in this category are the variables of neat, clean, and complete facilities. Of the three variables, clean is the most dominant variable. So, it is necessary to pay attention to how the management of public space is maintained so that the environment is kept clean.

Novelty is the next dominant category, which includes only the distinctive values or values that only the public space has. The variables included are unique, curious, new atmosphere, aesthetic, photogenic, night atmosphere, and famous with aesthetics as the most dominant variable. Of course, the role of the architect is very strong here.

After novelty, parking is the dominant variable. What is meant by this variable is the availability of parking in the public space.

The last dominant variable is many choices. Many choices represent variables related to retail variations in these public spaces and their characteristics. The variables included are food, shop, and affordable prices. This means that a good public space must provide a variety of food and shops at affordable prices. Among the three attractions, the most dominant is food. So, it is very important to pay attention to the diversity of food in a public space.

The last category is art. Art includes things that are artistic in the public space. This category describes how visitors there can learn about the culture and the existence of craft fairs. However, this category is not considered dominant considering that the mean is below the median. This means that the public space tends not to have this attraction.

From these eight factors, we can see several problems in designing a public space based on its physical characteristics. Of course, what can be said as a design problem is a dominant category. So that we can say that the design issues include ambiance in the form of a social and natural environment, accessibility, novelty, diversity which includes many choices, as well as facilities in the form of tidiness, cleanliness, and parking availability.

This is in line with the finding of five basic needs that can meet visitor satisfaction in public spaces by Stephen Carr (1992). The first is convenience, where the results of this study include the natural environment, accessibility, neatness and cleanness, and parking. The second need is relaxation, which is psychological comfort that also includes the natural environment. The third need is passive attachment, which is attachment to the environment that can cause a feeling of relaxation but is different from meeting location-related needs. The results of research included in this need are the natural environment and the arts. The fourth need is active attachment, namely direct experience with the environment that includes the social atmosphere. The last is the need for discovery which represents the desire to have new experiences. This need includes novelty and many choices. Furthermore, the comparison of these findings can be seen in Table 4 below. 
Table 4. Comparison of Basic Needs for Public Space

\begin{tabular}{ll}
\hline Carr (1992) & Author (2020) \\
\hline \multirow{2}{*}{ Convenience } & Natural environment \\
& Accessibility \\
& Neat and clean \\
& Parking \\
\hline Relaxation & Natural environment \\
\hline \multirow{2}{*}{ Passive Attachment } & Natural environment \\
\hline Active Attachment & Art \\
\hline \multirow{2}{*}{ Discovery } & Social atmosphere \\
\hline & Novelty \\
& Many choices \\
\hline
\end{tabular}

\section{Activities Dimension}

Based on the factor analysis regarding activities, it was found that six main components (Table 5) with eigenvalues of more than one were considered sufficient to represent the phenomenon of 23 measured variables (Table 6). Six dimensions that represent motivational activities to visit public spaces are refreshing, recreation, productive, consumptive, socialization, as well as exercise and playing.

Table 5. Factor Analysis of Activity in Public Spaces

\begin{tabular}{lcccccc}
\hline & Refreshing & Recreation & Productive & Consumptive & $\begin{array}{c}\text { Socia- } \\
\text { lization }\end{array}$ & $\begin{array}{c}\text { Exercise } \\
\text { and } \\
\text { Playing }\end{array}$ \\
\hline Mean & 3,57 & 3,54 & 2,65 & 2,55 & 3,43 & 3,07 \\
\hline $\boldsymbol{\alpha}$-Cronbach & 0,88 & 0,78 & 0,76 & 0,73 & 0,60 & 0,36 \\
\hline Variance & 4,40 & 3,17 & 3,11 & 2,23 & 1,91 & 1,78 \\
\hline Cum percent & 17,59 & 30,25 & 42,69 & 51,61 & 59,24 & 66,34 \\
\hline \multicolumn{7}{c}{ Source: Dea and Kusuma, 2021 } \\
\end{tabular}

From the results of the factor analysis, it can be seen that refreshing is the most dominant category because the mean is the highest compared to other categories. This category describes passive self-refreshing activities, such as relaxation, getting fresh air, needing refreshing, relaxing, healing, recreation, and looking for inspiration. Out of the many variables, the most dominant one is that it requires refreshing (Table 6). This variable is followed by the relaxing variable. So, it is necessary to pay attention to how public space can accommodate visitors to be refreshed, especially by providing a place to relax. 
Table 6. Mean and Loading Factor of Each Activity Variables

\begin{tabular}{|c|c|c|c|}
\hline Dimensions & Variable & Mean & Loading Factor \\
\hline \multirow{7}{*}{ Refreshing } & Relaxation & 3,6 & 0,87 \\
\hline & Getting fresh air & 3,7 & 0,82 \\
\hline & Need refreshing & 3,98 & 0,74 \\
\hline & Relaxing & 3,75 & 0,73 \\
\hline & Healing & 3,4 & 0,69 \\
\hline & Recreating & 3,25 & 0,61 \\
\hline & Looking for Inspiration & 3,33 & 0,57 \\
\hline \multirow{6}{*}{ Recreation } & Sight-seeing & 3,73 & 0,76 \\
\hline & Bored & 3,7 & 0,69 \\
\hline & Strolling & 3,83 & 0,67 \\
\hline & Entertainment & 3,64 & 0,61 \\
\hline & Watching activity & 3,56 & 0,49 \\
\hline & Photo hunting & 2,78 & 0,47 \\
\hline \multirow{4}{*}{ Productive } & Working & 2,28 & 0,81 \\
\hline & Learning culture & 2,36 & 0,78 \\
\hline & Attending event & 2,7 & 0,63 \\
\hline & Me time & 3,25 & 0,54 \\
\hline \multirow{3}{*}{ Consumptive } & Shopping & 2,31 & 0,81 \\
\hline & Culinary & 3,17 & 0,75 \\
\hline & Live music & 2,17 & 0,59 \\
\hline \multirow{2}{*}{ Socialization } & Meeting point & 3,16 & 0,73 \\
\hline & Socializing & 3,7 & 0,69 \\
\hline \multirow{2}{*}{ Exercise and Playing } & Exercising & 2,94 & 0,80 \\
\hline & Playing & 3,21 & 0,56 \\
\hline
\end{tabular}

Source: Dea and Kusuma, 2021

The refreshing category is followed by the recreation category whose definition is not much different. If refreshing is a passive self-refreshing activity, recreation is an active refreshing activity. This shows that indeed the main activity that a person does in the public space is to refresh himself. Included in the recreation category are sightseeing, avoiding boredom, strolling, looking for entertainment, observing activities, and photo hunting. The most dominant activities are strolling and sightseeing. 
The next dominant activity is socialization. Socialization is an activity that relates to other people, such as making public spaces a meeting point and a place to socialize, where socializing itself is the most dominant activity. This supports the previous most dominant physical characteristic, namely the social atmosphere.

Next are activities that tend to rely on physicality, namely exercise and playing. This category's mean is very close to or tends to be the same as the median. This means that this activity may be in a public space but not in another public space. As the name implies, this category includes exercise and playing activities, where play tends to be more dominant because the mean of exercise is below the median.

The next category is the category whose mean is below the median, meaning that these activities tend to be rarely found in public spaces. The first is the productive category. Productive includes activities that users can get or produce when doing it. Included in this category are working, learning culture, attending events, and me time. The most dominant activity is my time as the only variable whose mean is above the median.

Following productive, the consumptive category is the last variable of public space activities where this activity is rarely found. If productive is an activity that produces something, on the contrary, consumptive is an activity that spends things like shopping, culinary delights, and live music. If we look again at the characteristics of food as something that stands out in the public space, this is of course contradicting with culinary, which is the least dominant activity category. However, it can also be seen in Table 3 whereof the three activities in the consumptive category, culinary is the only activity whose mean is above the median. This means that these activities are often found in public spaces. However, other activities, namely shopping and live music, are less likely to be found.

From the six categories of activities, it can be seen what activities are important to be accommodated in the design of public space. These activities include refreshing, recreation, socialization, as well as exercise, and playing, considering that the four categories have a mean above the median. However, it should also be noted the measured variables included in the category are not dominant, but the individual mean is above the median, such as me time and culinary. It is also important to accommodate these two activities, especially since these activities are related to the previous dominant category in physical characteristics.

Table 7. Comparison of Activities in Public Spaces

\begin{tabular}{ll}
\hline Gehl (1987) & Author (2020) \\
\hline \multirow{2}{*}{ Main Activities } & Productive \\
& Consumptive \\
& Exercise and playing \\
\hline \multirow{2}{*}{ Optional Activities } & Refreshing \\
& Recreational activities \\
\hline Social Activities & Socializing \\
\hline
\end{tabular}

If we compare it (Table 7) with Jan Gehl's (1987) theory regarding three kinds of activities in the public space, namely main activities, choice activities, and social activities, the classification of the results of the factor analysis can be put into three Gehl's categories. Gehl described main activities as routine activities carried out 
because of necessity to fulfill certain needs. Therefore, productive, consumptive activities, as well as exercise and play tend to fall into this category. Meanwhile, optional activities are activities that are carried out when the opportunity or time is right and supportive. This category includes refreshing and recreational activities. The last is social activities, which are activities that involve interaction with other parties around them which include socialization activities.

\section{Sense of Place Dimension}

The last one is the PCA of the sense of place, which is then obtained three main categories with an eigenvalue of more than one which is considered sufficient to represent the phenomenon of 12 measurable variables. The three categories are dedication, meaningful, and just know-how whose factor analysis can be seen in Table 8 below.

Table 8. Factor Analysis of Sense of Place

\begin{tabular}{lccc}
\hline & Dedication & Meaningful & Just Know-how \\
\hline Mean & 2,54 & 3,57 & 2,17 \\
\hline $\boldsymbol{\alpha}$-Cronbach & 0,90 & 0,82 & 0,54 \\
\hline Variance & 3,39 & 3,04 & 1,49 \\
\hline Cum percent & 28,27 & 53,60 & 66,00 \\
\hline
\end{tabular}

Table 9. Mean and Loading Factor of Each Sense of Place Variables

\begin{tabular}{llcc}
\hline Dimensions & Variable & Mean & Loading Factor \\
\hline \multirow{3}{*}{ Dedication } & Commitment & 2,56 & 0,92 \\
& Dedication & 2,62 & 0,85 \\
& Sacrifice & 2,12 & 0,85 \\
& Play an active role & 2,85 & 0,78 \\
\hline \multirow{3}{*}{ Meaningful } & Feelings of longing & 3,18 & 0,78 \\
& The thing to be told & 3,81 & 0,76 \\
& Very meaningful & 3,09 & 0,74 \\
& Get used to it & 3,91 & 0,74 \\
& Satisfied & 3,86 & 0,65 \\
\hline \multirow{3}{*}{ Just Know-how } & Know the location & 2,44 & 0,85 \\
& Not memorable & 2,44 & 0,64 \\
& Loyalty & 1,66 & 0,54 \\
\hline
\end{tabular}


From the three categories, it can be seen that the meaningful dimension is the only dominant category of sense of place in a public space. This dimension represents the feeling that the public space is special to the user. Included in it are feelings of longing, there are things to tell, are very meaningful, feel used to, and feel satisfied. Of the various variables, the most dominant is the feeling of being used to it. This means that people feel that public space is meaningful to them because they are used to it.

The other two categories tend not to be perceived or rarely felt in a public space because the mean is below the median. The first is dedication. Dedication represents a further stage from the previous category, with measurable variables in the form of commitment, dedication, sacrifice, and an active role. The four variables indicate a strong dedication by users to the public space. The definition of dedication according to KBBI is the sacrifice of energy, thoughts, and time for the success of an endeavor or a noble goal. All the variables included in it were also below the median, with an active role as the variable with the highest mean.

The last dimension and least felt by visitors is the category of just know-how, in which there is no strong attachment between the user and the public space. This category includes variables only knowing the location, not being memorable, and loyalty. The mean of just knowing the location is the same as being unimpressive, but the loyalty variable is very minimal to be felt.

From this phenomenon, it can be concluded that in general, people feel that public space means something to them. These feelings tend to be over neutral. Citizens don't just know about these public spaces. The feeling is more than that, but not to the point of dedication.

The tendency of the research results corresponds to the seven levels of sense of place by Shamai (1991). The first level of Shamai, namely not having any sense of place, was not included in the research because it was considered less relevant. The second level, in the form of knowledge of being located in a place, is considered the same as the factor of just know-how. The meaningful factors include levels three to five, namely belonging to a place, attachment to a place, and identifying with the place goals. Meanwhile, dedication represents the sixth and seventh levels, namely involvement in a place and sacrifice for a place. More details can be seen in Table 10 below.

Table 10. Shamai's Sense of Place Comparison with Factor Analysis Results

\begin{tabular}{|c|c|}
\hline Shamai (1991) & Author (2020) \\
\hline Not having any sense of place & - \\
\hline $\begin{array}{l}\text { Knowledge of being located in a } \\
\text { place }\end{array}$ & Just Know-how \\
\hline Belonging to a place & \multirow{3}{*}{ Meaningful } \\
\hline Attachment to a place & \\
\hline Identifying with the place goals & \\
\hline $\begin{array}{l}\text { Involvement in a place } \\
\text { Sacrifice for a place }\end{array}$ & Dedication \\
\hline
\end{tabular}




\section{Correlation between Physical Characteristics, Activity, and Sense of Place}

Furthermore, the three dimensions of physical characteristics, activity, and sense of place were analyzed using multivariate correlation analysis to see the causal relationship between the three dimensions. The results of the multivariate correlation analysis between the three factors can be seen in Table 11 below. Table 11 shows the correlation coefficient value. As the number becomes higher, the correlation becomes higher as well. The value of the correlation coefficient is between 0 to 1 , either positive or negative. The asterisk next to the correlation coefficient is an indicator of the significant value. The significant values are shown in table 11.

Table 11. Multivariate Correlation of Physical Characteristics, Activity, and Sense of Place

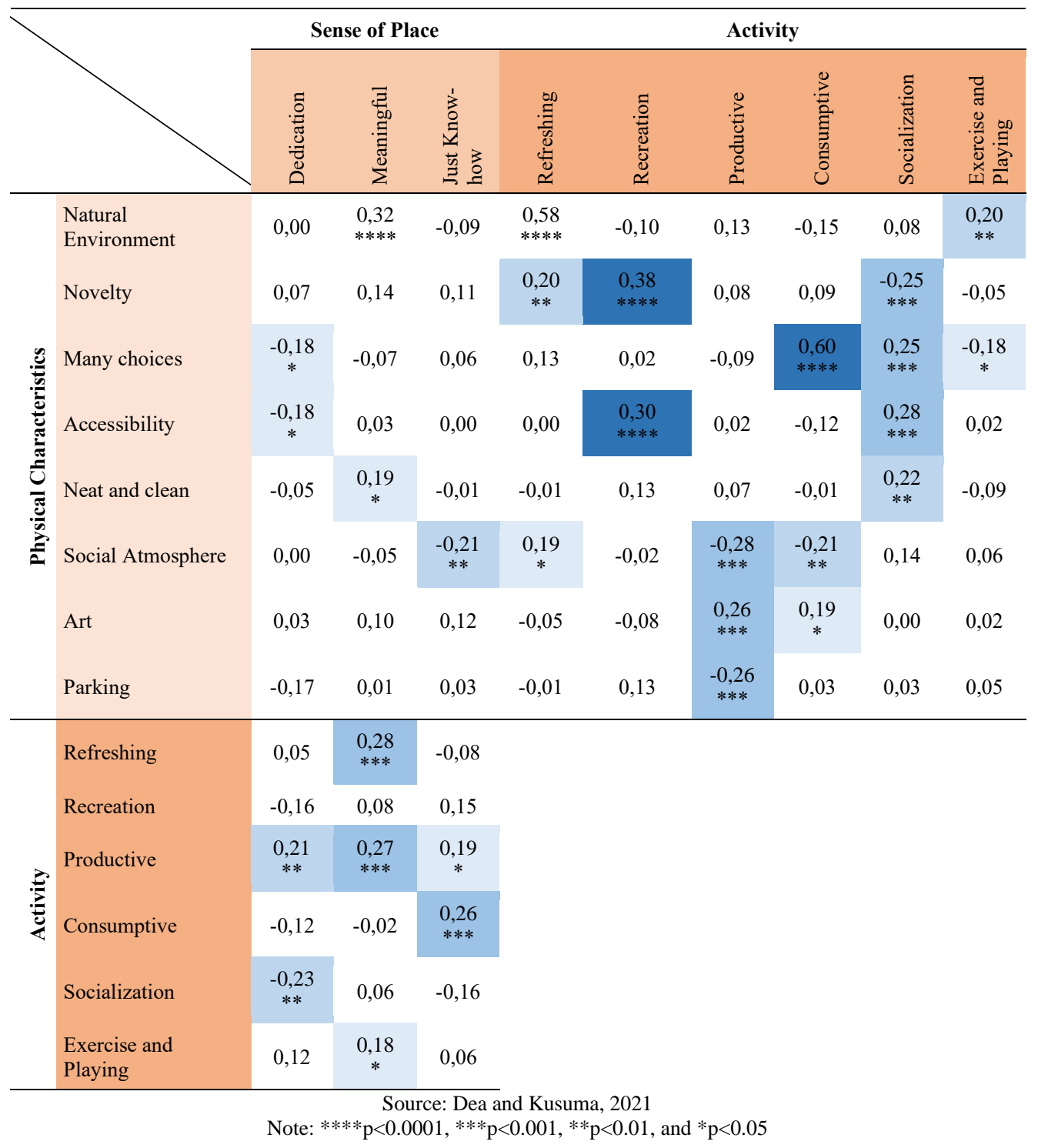


From the results of the analysis, it can be seen that physical characteristics have a strong influence on the sense of place and activities in public spaces. This is in line with Weisman's (1981) statement which states that environmental attributes affect user behavior in public spaces. The results also support the research results of Adhitama (2013) that physical settings determine users in their activities in public spaces. In addition, activities also have a strong influence on the sense of place. This is certainly in line with Beqaj's (2016) statement that the quality of public space is closely related to the framework of activities that develop in it. This means that the quality of public spaces can be seen from the user's sense of place for these public spaces. To simplify the analysis, a model was created that represented the results of the multivariate correlation analysis (Figure 1).

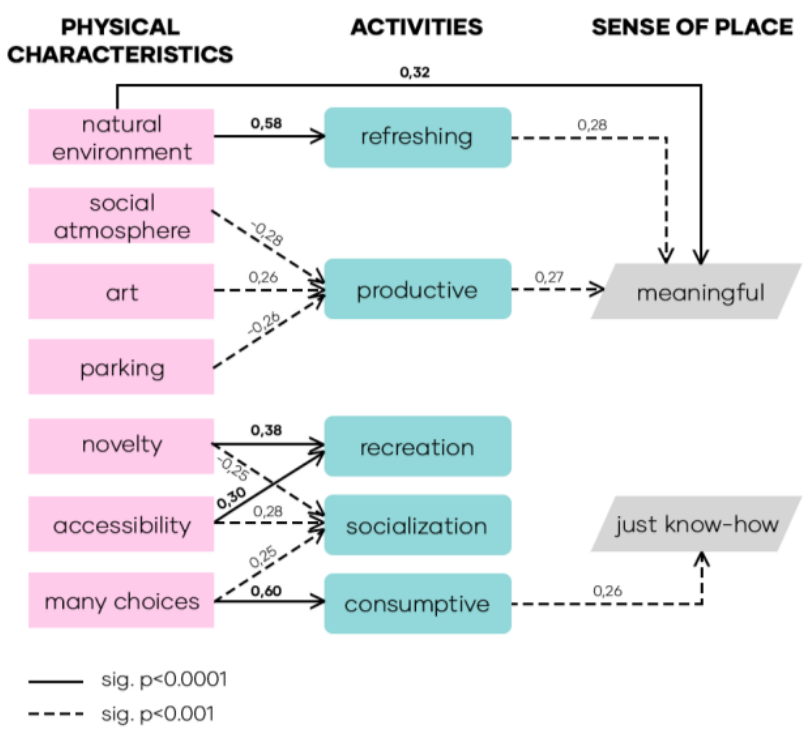

Figure 1. Correlational Relationships between Physical Characteristics, Activity, and Sense of Place

Source: Dea and Kusuma, 2021

The natural environment $(\mathrm{r}=0.58 ; \mathrm{p}<0.0001)$ has a strong influence on refreshing activities that encourage $(r=0.28 ; \mathrm{p}<0.001)$ a sense of meaningful. In addition, it seems that the natural environment also has a strong direct effect $(\mathrm{r}=$ $0.32 ; \mathrm{p}<0.0001)$ on the sense of meaning. This is following the theory of Kaplan and Kaplan (1995) that nature has a greater restorative potential than artificial components. Galindo (2000) also states that the satisfaction from nature that encourages people to have fun has a positive influence on one's psychological behavior.

In addition, a sense of meaning was also driven by productive activities $(\mathrm{r}=$ 0.27; $\mathrm{p}<0.001$ ). These results support Beqaj's (2016) statement that the public space is a place for fun, work, debate, argument, and policy where emotional, social, and physical needs can be met. He also mentioned usability as one of the qualities of public space, so that the public space is useful for visitors to carry out their needs. This productive activity is driven by physical characteristics in the form of art ( $\mathrm{r}=$ $0.26 ; \mathrm{p}<0.001)$. With an artistic atmosphere, visitors can be more inspired to do 
productive things. However, this productive activity was negatively affected by the social atmosphere $(\mathrm{r}=-0.28 ; \mathrm{p}<0.001)$ and parking $(\mathrm{r}=-0.26 ; \mathrm{p}<0.001)$. With a diverse and busy social atmosphere, visitors tend to be distracted when doing productive things. The availability of a parking area is likely to make the area more polluted so that it makes visitors less appetizing for productive things.

The physical characteristics of novelty strongly encourage $(r=0.38 ; p$ $<0.0001)$ recreational activities but have a negative effect on socialization activities $(\mathrm{r}=-0.25 ; \mathrm{p}<0.001)$. When there is something novel, people tend to explore so that indirectly they do recreational activities there. However, it hinders socialization because people tend to interact socially in the places and atmosphere they are used to. Cross (2001) says that a sense of place develops because of habit or familiarity with the surrounding environment. Apart from novelty, recreation is also strongly driven by physical characteristics in the form of accessibility $(r=0.30 ; p<0.0001)$. People will tend to move to a place that is easily accessible. In addition, accessibility also encourages socialization activities $(\mathrm{r}=0.28$; $\mathrm{p}<0.001)$ because it will be easy to meet other people in a place that is easily accessible for both parties. Not surprisingly, Whyte (2000) states that accessibility is the most important factor in determining the success of public space, although it turns out that from the research results this factor does not have a direct effect.

Finally, physical characteristics in the form of many choices that encourage socialization activities $(\mathrm{r}=0.25 ; \mathrm{p}<0.001)$ and strongly encourage consumptive activities $(r=0.60 ; \mathrm{p}<0.0001)$. People tend to socialize in a place that has a variety of shops and affordable food, so they also have a variety of options for spending time in it with partners who may have different tastes. Of course, the variety of shops and food at affordable prices also makes people behave more consumptively. Visitors will be attracted when they see diverse goods and foods and have the intention to try or have several types, especially when they are sold at affordable prices. This consumptive activity also affects the visitor's attachment to the public space $(r=0.26 ; p<0.001)$, but it is limited to just know-how.

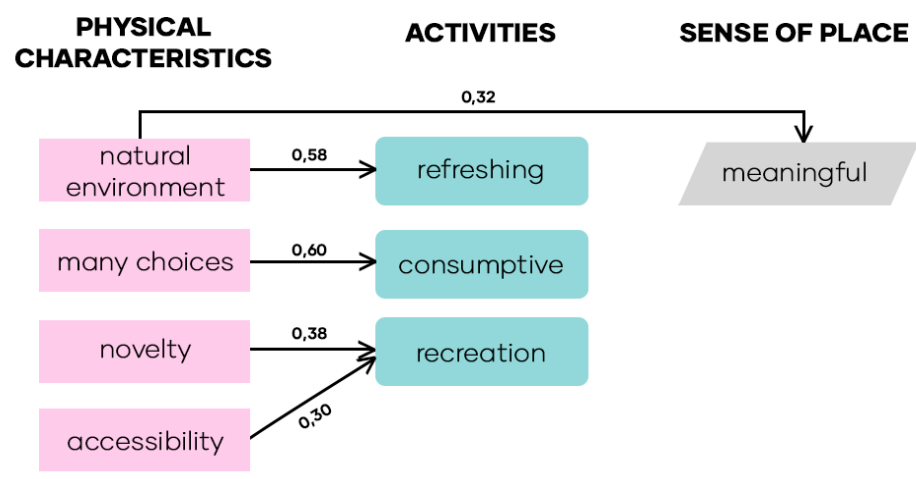

Figure 2. Correlational Relationship with Significance $<0.0001$ Source: Dea and Kusuma, 2021

From these various phenomena, a simpler model was made again (Figure 2) to describe the very high and most dominant correlation, that is, the one whose significance value is less than 0.0001. Through this model, a summary of the correlation between the three dimensions can be seen, where the only sense of place that is correlated with other dimensions is a sense of meaning which is only driven 
by the physical characteristics of the natural environment. This natural environment also encourages refreshing activities so that it can be said to be the only variable that encourages two categories, namely activity and a sense of place. The remaining correlations tend to be physical characteristics that drive activity. Examples are consumptive activities driven by many choices, as well as recreational activities are driven by novelty and accessibility.

In general, it can be concluded that the sense of place for public spaces is influenced by the motivation to visit public spaces, both the physical characteristics contained in these public spaces and the activities that can occur in them. These physical characteristics can directly influence the sense of place, or indirectly; namely through activities which then encourage a sense of place. However, activities that encourage a sense of place must also be motivated by physical characteristics. However, not all physical characteristics and activities encourage a sense of place. There are physical characteristics that only encourage the activity stage.

\section{CONCLUSION}

Research reveals a correlational relationship between physical characteristics, activities, and the sense of place of public space. Sense of place is driven by physical characteristics and activities in the public space. Physical characteristics can encourage a sense of place directly or through activities that then encourage a sense of place. However, any activity that encourages a sense of place must have physical characteristics that encourage it.

The example is a natural environment that encourages a sense of meaningfulness directly. However, the natural environment also encourages refreshing activities which in turn also create a sense of meaning. Productive activities also encourage a sense of meaning. Behind these productive activities, there are physical characteristics in the form of art that encourage activities, as well as a social atmosphere and parking that have a negative effect.

It was also found that the physical characteristics of novelty encourage recreation but hinder socialization activities. In addition, recreational and socialization activities are also driven by accessibility. However, recreational and socialization activities have no connection with any sense of place. The characteristics of many choices encourage socialization and consumptive activities which then create a sense of place just know-how.

The research still has several shortcomings, such as the use of non-random sampling methods which then has an impact on the uneven distribution of respondents. Even though in terms of gender it is quite balanced, the distribution of age, occupation, and domicile is still not evenly distributed, so it is feared that it will affect the physical characteristics available and especially the activities that can be carried out. Considering the activities that may be carried out by each generation are different, especially in different cities because of the different climatic contexts. Therefore, the level of reliability still needs to be improved through further research, one of which is the use of the random sampling method. 


\section{REFERENCES}

Adhitama, M. S. (2014) Faktor Penentu Setting Fisik Dalam Beraktifitas di Ruang Terbuka Publik "Studi Kasus Alun-Alun Merdeka Kota Malang", RUAS (Review of Urbanism and Architectural Studies), 11(2), 1-9, Department of Architecture of Universitas Brawijaya, Malang.

Androulaki, M., Frangedaki, E., and Antoniadis, P. (2020) Optimization of public spaces through network potentials of communities, Procedia Manufacturing, 44, 294-301, Elsevier BV, Amsterdam.

Beqaj, B. (2016) Public Space, Public Interest and Challenges of Urban Transformation, IFAC-papers online, 49 (29), 320-324, IFAC, Geneva.

Carmona, M., De Magalhaes, C., and Hammond, L. (2007) Public Space, Routledge, London.

Carr, S., et al. (1992) Public Space, Press Syndicate of University of Cambridge, Australia

Creswell, J.W. (2011) Educational Research: Planning, Conducting and Evaluating Quantitative and Qualitative Research, MA Pearson Education, Boston.

Creswell, J. W. (2012) Educational research: Planning, conducting, and evaluating quantitative and qualitative research (4th ed.), M.A. Pearson, Boston.

Francis, M. (1988) Changing values for public spaces, Landscape Architecture, 78(1), 54-59.

Galindo, M.P.G. and Rodríguez, J.A.C. (2000) Environmental Aesthetics and Psychological Wellbeing: Relationships between Preference Judgements for Urban Landscapes and Other Relevant Affective Responses, Psychology in Spain, 4(1), 13-27, Colegio Oficial de Psicólogos, Madrid.

Gehl, J. (1987) Life Between Buildings: Using Public Space, Van Nostrand Reinhold, New York.

Haider, J. and Kaplan, M. (2004) Reclaiming open space for the young: An intergenerational perspective on design, Proceeding for the open space people space-International Conference on Inclusive Outdoor Environments, 171176, October 27-29 2004, Edinburgh Scotland.

Hantono, D. (2017) Pola Aktivitas Ruang Terbuka Publik pada Kawasan Taman Fatahillah Jakarta, Jurnal Arsitektur KOMPOSISI, 11 (6), 265-277, Program Studi Arsitektur Universitas Atma Jaya Yogyakarta, Yogyakarta.

Hantono, D. (2019) Kajian Perilaku pada Ruang Terbuka Publik, NALARs Jurnal Arsitektur, 18 (1), 45-56, Arsitektur Universitas Muhammadiyah Jakarta, Jakarta.

Haryanti, D. T. (2008) Kajian Pola Pemanfaatan Ruang Terbuka Publik Kawasan Bundaran Simpang Lima Semarang, Doctoral Dissertation, Universitas Diponegoro, Semarang.

Iswanto, D. (2006) Kajian Ruang Publik Ditinjau dari Segi Proporsi / Skala dan Enclosure, Jurnal Ilmiah Perancangan Kota dan Permukiman ENCLOSURE, 5 (2), 74-81, Universitas Diponegoro, Semarang.

Kaplan, R. and Kaplan, S. (1989) The experience of nature: A psychological perspective, Cambridge University Press, New York. 
Kaplan, M. S., Henkin, N. Z. and Kusano, A. T. (2002) A conceptual framework for cross-cultural comparisons of intergenerational initiatives. Linking Lifetimes: A global view of an intergenerational exchange, University Press of America, Lanham.

Kumar, R. (2005) Research Methodology: A Step by Step Guide for Beginner, Sage Publications, London.

Meagher, B. R., and Marsh, K. L. (2017) Seeking the Safety of Sociofugal Space: Environmental Design Preferences Following Social Ostracism, Journal of Experimental Social Psychology, 68, 192-199, Elsevier, Amsterdam.

Permanasari, E. and Lientino, T. (2019) Transformasi Makna dan Fungsi Ruang di RPTRA Kalijodo dalam Pergulatan Citra Kota Jakarta, RUAS (Review of Urbanism and Architectural Studies), 16 (2), 13-27, Department of Architecture of Universitas Brawijaya, Malang.

Petrescu, D., Petcou, C. and Baibarac, C. (2016) Co-producing commons-based resilience: lessons from R-Urban, Building Research \& Information, 44(7), 717-736, Taylor and Francis Ltd, Oxfordshire.

Prihutami, D. (2008) Ruang Publik Kota yang Berhasil, Thesis, Universitas Indonesia, Depok.

Rossi, A. (1986) The Architecture of the City, The MIT Press, US.

Rully. (2016) Peran Public Space sebagai Upaya Peningkatan Partisipasi Masyarakat dalam Menjaga Lingkungan Binaan Kota, Jurnal Teknik Sipil dan Arsitektur, 19 (23), Universitas Tunas Pembangunan, Surakarta.

Sari, D. K. and Siahainenia, R. R. (2015) Gerakan Sosial Baru di Ruang Publik Virtual pada Kasus Satinah, Jurnal Ilmu Komunikasi, 12 (1), 105-118, Universitas Atma Jaya Yogyakarta, Yogyakarta.

Setiawan, B. B. (2006) Ruang Publik dan Modal Sosial: Privatisasi dan Komodifikasi Ruang di Kampung, UNISIA, 0 (59), 28-38, Universitas Islam Indonesia, Yogyakarta.

Shaftoe, H. (2008) Convivial Urban Spaces: Creating Effective Public Spaces, Earthscan, London.

Shamai, S. (1991) Sense of place: An empirical measurement, Geoforum, 22(3), 347-358, Elsevier, Amsterdam.

Weisman, G. D. (1981) Man Environment Model, Journal of Man-Environment Relations, 1(2), Pennsylvania State University, Pennsylvania.

Wirasmoyo, W. (2017) Optimasi Lahan Terlantar menjadi Ruang Publik di Kampung Kota, Jurnal Arsitektur KOMPOSISI, 11 (5), 217-225, Universitas Atma Jaya Yogyakarta, Yogyakarta. 